\title{
A component model for the behaviour of steel joints at elevated temperatures
}

\author{
L. Simões da Silva ${ }^{a, *}$, Aldina Santiago ${ }^{\text {b }}$, Paulo Vila Real ${ }^{\mathrm{c}}$ \\ ${ }^{a}$ Civil Engineering Department, University of Coimbra, Polo II, Pinhal de Marrocos, 3030 Coimbra, \\ Portugal \\ ${ }^{\mathrm{b}}$ Civil Engineering Department, University of Beira Interior, Edificio II das Engenharias, \\ Calçada do Lameiro, 6200 Covilhã, Portugal \\ ${ }^{\mathrm{c} C i v i l ~ E n g i n e e r i n g ~ D e p a r t m e n t, ~ U n i v e r s i t y ~ o f ~ A v e i r o, ~ C a m p o ~ d e ~ S a n t i a g o, ~} 3810$ Aveiro, Portugal
}

Received 8 January 2001; received in revised form 7 June 2001; accepted 2 August 2001

\begin{abstract}
Recent experimental evidence has shown that steel joints exhibit a distinct change in their moment-rotation response under increasing temperature. In terms of cold design, the component method is currently the widely accepted procedure for the evaluation of the various design values. It is the purpose of the present paper to extend the component method to the prediction of the response of steel joints under fire loading. Using typical mechanical models consisting of extensional springs and rigid links, whereby the springs exhibit a non-linear force deformation response (here taken as a bi-linear approximation), an analytical procedure is proposed capable of predicting the moment-rotation response under fire conditions that incorporates the variation of yield stress and Young's modulus of the various components as the temperature increases. An application to a cruciform flush end-plate beam-to-column steel joint is presented and compared to the experimental results obtained under various loading conditions. (C) 2001 Elsevier Science Ltd. All rights reserved.
\end{abstract}

Keywords: Steel joints; Steel structures; Fire resistance; Component method

\section{Introduction}

Recent research on the behaviour of steel structures under fire loading highlighted the influence of joint behaviour on the overall response of the structure [1]. The lack of experimental results on the response of steel joints under fire conditions and the

\footnotetext{
* Corresponding author. Tel.: +351-239-797216; fax: +351-239-797217.

E-mail address: luis_silva@gipac.pt (L. Simões da Silva).
} 


\section{Nomenclature}

$b_{\text {eff,c,wc }}$ effective width of the column web in compression zone

$b_{\text {eff,t,wb }}$ effective width of the beam web in tension zone

$b_{\text {eff,t,wc }}$ effective width of the column web in tension zone

$d$ nominal diameter of the bolts

$d_{\mathrm{c}} \quad$ clear depth of the column web

$d_{\mathrm{M} 16}$ nominal diameter of a M16 bolt

$f_{\mathrm{p}, \theta} \quad$ proportional limit

$f_{\mathrm{ub}} \quad$ ultimate tensile strength of the bolts

$f_{\mathrm{y}} \quad$ yield stress

$f_{\mathrm{y}, \mathrm{wb}} \quad$ yield stress of a beam web

$f_{\mathrm{y}, \mathrm{wc}} \quad$ yield stress of a column web

$f_{\mathrm{y}, \theta} \quad$ effective yield strength

$k_{E ; \theta} \quad$ reduction factor (relative to $E$ ) for the slope of the linear elastic range

$k_{i} \quad$ stiffness coefficients for basic joint components according to Part $1.8, \mathrm{EC} 3$

$k_{\mathrm{y} ; \theta} \quad$ reduction factor (relative to $f_{\mathrm{y}}$ ) for effective yield strength

$l_{\text {eff }} \quad$ smallest of the effective lengths (individually or as part of a bolt group)

$m \quad$ distance between the bolt centre line and the face of the weld connecting the beam web to the end-plate; number of fraying surfaces or shear planes in a bolted joint, equal to 1.0 for bolts in single shear and 2.0 for bolts in double shear

$n_{\mathrm{b}} \quad$ number of bolt-rows

$t_{\mathrm{fc}} \quad$ thickness of column flange

$t_{\mathrm{p}} \quad$ plate thickness

$t_{\mathrm{wb}} \quad$ thickness of beam web

$t_{\mathrm{wc}} \quad$ thickness of column web

$z \quad$ lever arm, see Part 1.8, EC3

A cross-section area

$A_{\mathrm{s}} \quad$ tensile stress area of the bolt

$A_{\mathrm{vc}} \quad$ shear area of the column

E Young's modulus

$F^{\mathrm{f}} \quad$ applied force that corresponds to failure

$F^{\mathrm{y}} \quad$ applied force that corresponds to yield

$K^{\mathrm{e}} \quad$ elastic stiffness of the component, obtained from the following: $k_{i} \times E$, according to Part 1.8, EC3

$K^{\mathrm{pl}} \quad$ post-limit stiffness of the component

$L_{\mathrm{b}} \quad$ bolt elongation length, taken as equal to the grip length (total thickness of material and washers), plus half the sum of the height of the bolt head and the height of the nut 


\begin{tabular}{|c|c|}
\hline$M$ & applied moment \\
\hline$M_{\mathrm{c}, \mathrm{Rd}}$ & $\begin{array}{l}\text { moment resistance of the beam cross-section, reduced if necessary } \\
\text { to allow for shear, see } 5.4 .5 \text { and } 5.4 .7, \text { EC } 3\end{array}$ \\
\hline$\beta$ & transformation parameter, see Part 1.8, EC3 \\
\hline$\beta_{\mathrm{w}}$ & correlation factor \\
\hline$\gamma_{M 0}$ & $\begin{array}{l}\text { partial safety factor for resistance of class } 1,2 \text { or } 3 \text { cross-section } \\
(=1.1)\end{array}$ \\
\hline$\gamma_{M 1}$ & $\begin{array}{l}\text { partial safety factor for resistance of member to buckling or } \\
\text { resistance of class } 4 \text { cross-section }(=1.1)\end{array}$ \\
\hline$\gamma_{M \mathrm{~b}}$ & partial safety factor for resistance of bolted connections $(=1.25)$ \\
\hline$\gamma_{M \mathrm{w}}$ & partial safety factor for resistance of welded connections $(=1.25)$ \\
\hline$\varepsilon$ & strain \\
\hline$\varepsilon_{\mathrm{p}, \theta}$ & strain at the proportional limit \\
\hline$\varepsilon_{\mathrm{t}, \theta}$ & limiting strain for yield strength \\
\hline$\varepsilon_{\mathrm{u}, \theta}$ & ultimate strain \\
\hline$\varepsilon_{\mathrm{y}, \boldsymbol{\theta}}$ & yield strain \\
\hline$\theta$ & temperature \\
\hline$v$ & Poisson's ratio \\
\hline$\rho$ & reduction factor for plate buckling \\
\hline$\varphi^{\mathrm{f}}$ & rotation that corresponds to failure \\
\hline$\varphi^{\mathrm{y}}$ & rotation that corresponds to yield \\
\hline$\omega$ & $\begin{array}{l}\text { reduction factor to allow for the possible effects of shear in the } \\
\text { column web panel }\end{array}$ \\
\hline$\Delta^{\mathrm{y}}$ & deformation that corresponds to yield \\
\hline$\Delta^{\mathrm{f}}$ & deformation that corresponds to failure \\
\hline$\Delta_{\mathrm{i}}$ & deformation for basic joint components \\
\hline
\end{tabular}

use of numerical models relying on empirical relations established from tests either at room temperature, or for a limited range of (low) temperatures, has led to a simplistic specification from the current codes of practice. In fact, according to Eurocode 3, Part 1.2 [2] and draft 2 of Part 1.8 [3], the concentration of mass within the joint area, when compared to the connecting members, delays its temperature increase, therefore suggesting that joints could be disregarded under fire conditions. However, in contrast to the EC3 specification, recent experimental results [4,5] have highlighted the need to evaluate the behaviour of steel joints at elevated temperatures, since they exhibit a pronounced reduction of strength and stiffness that clearly affects the global response of the structure.

It is never enough to repeat that the behaviour of joints is complex, falling between the traditional assumption of pinned and fully rigid response. A considerable effort was undertaken over the past two decades to give consistent predictions of the behaviour of steel joints. However, until now, most research studies on the behaviour of semi-rigid joints were focused on determining resistance and stiffness characteristics 
[6], leading to the code specifications for the evaluation of strength and stiffness of steel and composite joints that were prepared for Eurocodes 3 and 4 [2,3,7].

Naturally, any attempt at predicting the behaviour of a steel connection under fire loading, already complex at room temperature [8], is further complicated by several phenomena:

1. variation of material properties of steel with temperature;

2. accurate prediction of time-temperature variation within the various joint components;

3. differential elongation of the various joint components because of increasing temperature;

4. proper definition of fire development models within the building envelope and subsequent time-temperature profiles reaching the joint.

Clearly, item (4) involves the architectural layout of the building and the particular fire event and lies outside the scope of this paper, a thorough treatment being found elsewhere [9]. Items (1)-(3) are strictly required to predict the moment-rotation response of steel joints and are discussed in the following sections, in the context of an approach based on the so-called "component method" [10], proposed in this paper to predict the behaviour of steel joints under fire loading, described below.

\section{Component model}

\subsection{Component method}

To overcome the need to implement complex non-linear finite element analysis in the prediction of the moment-rotation response of steel joints, a simpler approach was developed in the form of the so-called "component method" $[8,11,12]$. Briefly described, the method consists of modelling a joint as an assembly of extensional springs and rigid links, whereby the springs (components) represent a specific part of a joint that, dependent on the type of loading, make an identified contribution to one or more of its structural properties [10]. The application of the method to a typical cruciform bolted end-plate beam-to-column joint is illustrated in Fig. 1, the various components contributing to the overall response of a generic end-plate beamto-column steel joint being: (1) column web in shear, (2) column web in compression, (3) column web in tension, (4) column flange in bending, (5) end-plate in bending, (7) beam or column flange and web in compression, (8) beam web in tension, (9) plate in tension or compression, (10) bolts in tension, (11) bolts in shear and (19) welds.

\subsection{Component characterisation}

A key aspect to the component method relates to the characterisation of the forcedeformation curves for each individual extensional spring. Following [13], the vari- 

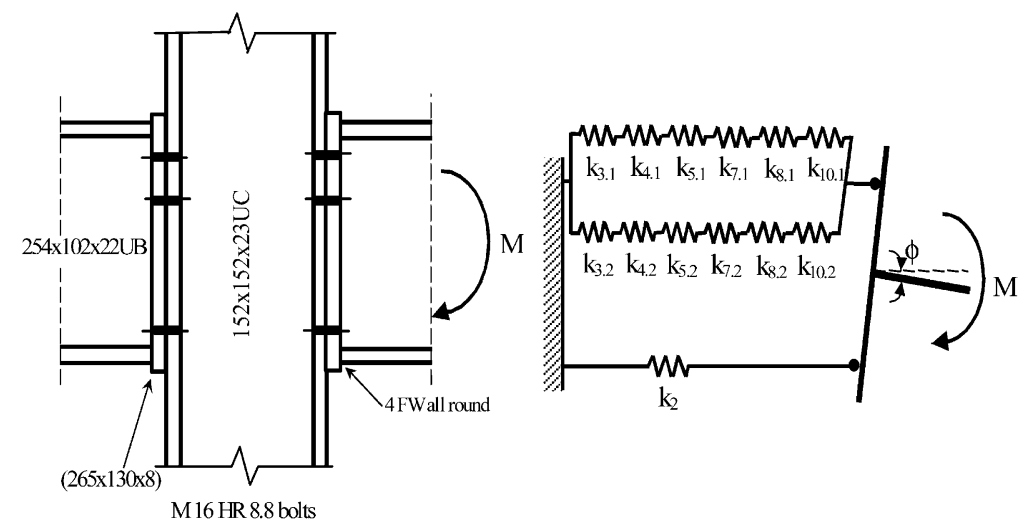

Fig. 1. Cruciform bolted end-plate beam-to-column [20]: (a) geometry of joint; (b) mechanical model.

ous components relevant for steel joints are classified in three main groups: (a) components with high ductility, (b) components with limited ductility; and (c) components with brittle failure. Common to all is the identification of four properties, namely elastic stiffness $\left(K^{\mathrm{e}}\right)$, post-limit stiffness $\left(K^{\mathrm{pl}}\right)$, limit load $\left(F^{\mathrm{y}}\right)$, yield displacement $\left(\Delta^{y}\right)$ and limit displacement $\left(\Delta^{f}\right)$, as seen in Fig. 2.

Components with high ductility present a force-deformation curve that changes from an initial linear elastic mode into a second carrying mode, which allows increasing deformation with increasing force [6]. The deformation capacity of the component is nearly unlimited, not imposing any bounds on the overall rotation ability of

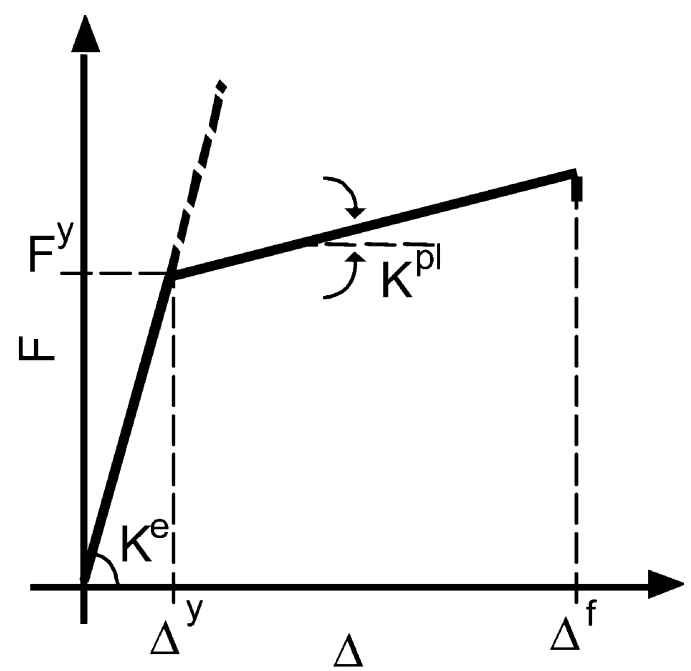

Fig. 2. Bi-linear characterisation of component behaviour. 
(a)

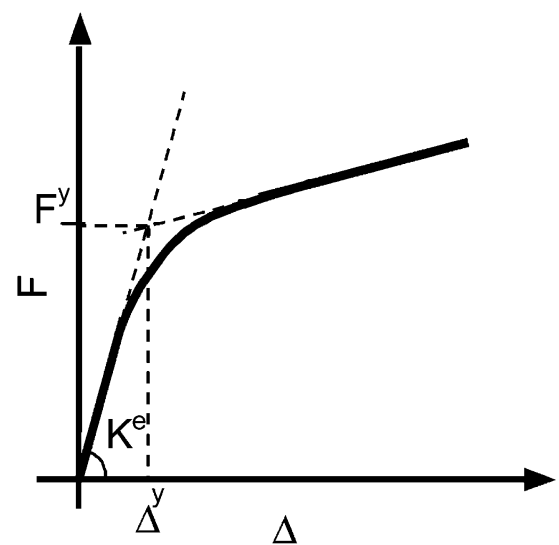

(b)

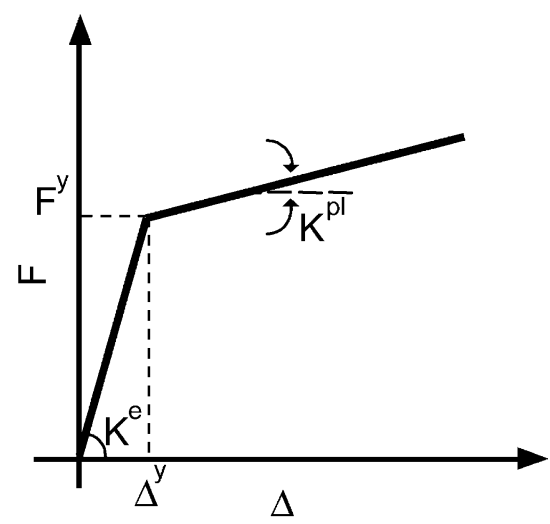

Fig. 3. Components with high ductility: (a) actual behaviour; (b) bi-linear approximation.

the joint, and is typically illustrated in Fig. 3(a) or, as a bi-linear approximation, in Fig. 3(b). Components falling into this classification include: (i) column web panel in shear, (ii, iii) beam and web in tension, (iv) end-plate in bending, and (v) column flange in bending, the latter two being usually evaluated using a simple substitute model, the T-stub [11].

Components with limited ductility are characterised by a force-deformation curve exhibiting a limit point and a subsequent softening response, as shown in Fig. 4(a) or, as a bi-linear approximation, in Fig. 4(b), and comprise: (vi) column web in compression and (vii) beam flange/web in compression.

Components with brittle failure behave linearly until collapse, with very little deformation before failure, as shown in Fig. 5(a) or, as a linear approximation, in

(a)

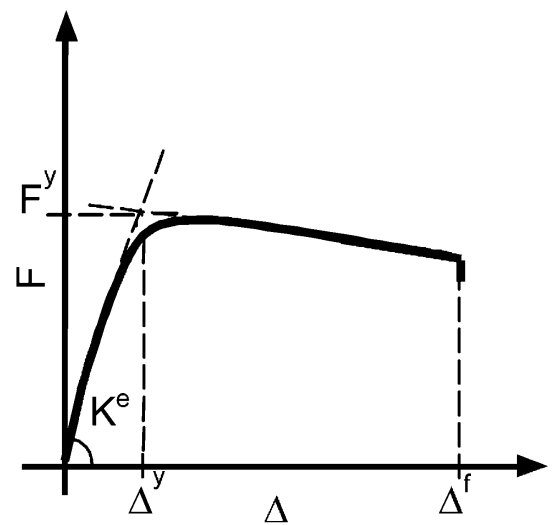

(b)

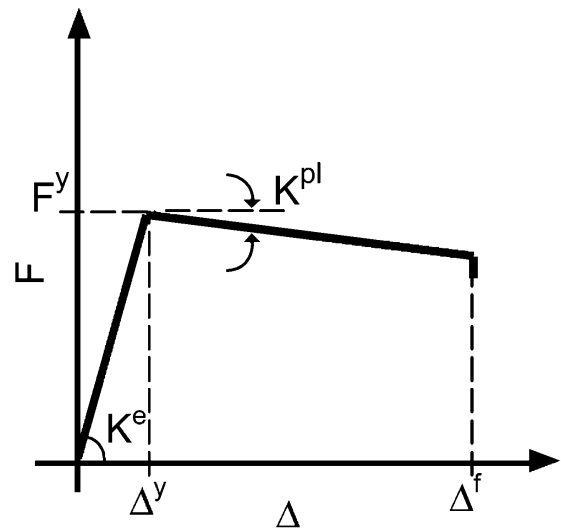

Fig. 4. Components with limited ductility: (a) actual behaviour; (b) bi-linear approximation. 
Fig. 5(b), typical examples being: (viii) bolts in tension, (ix) bolts in shear, and (x) welds.

(a)

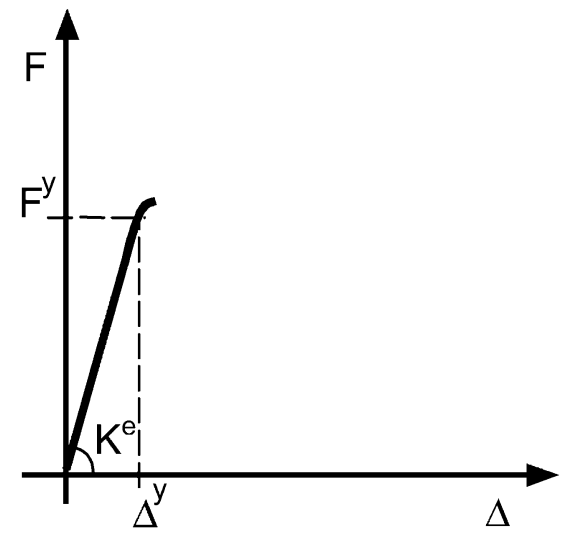

(b)

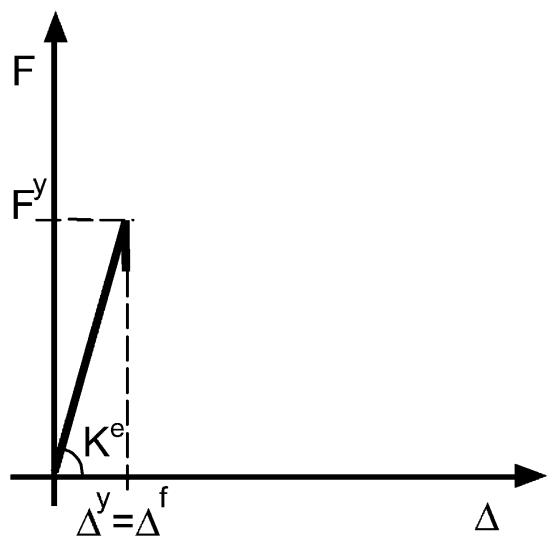

Fig. 5. Components with brittle failure: (a) actual behaviour; (b) linear approximation.

The design properties (resistance and initial stiffness) of the various components can be found in Part 1.8 of EC3 [3] and are summarised in Table 1, little or no guidance currently being available for the remaining properties [8].

\subsection{Joint response under flexural loading}

The assessment of the moment-rotation response of steel joints requires a nonlinear procedure, which incorporates the non-linear features of each component. This can be achieved by statical analysis of the mechanical system of Fig. 1, either using a numerical analysis with a non-linear finite element program or the recently developed closed-form analytical procedures $[8,14]$. Here, it will be assumed that the momentrotation response of a steel joint at room temperature is already available, clearly identifying the various changes of stiffness corresponding to an assumed bi-linear approximation for the force-displacement response of each spring (component), as typically shown in Fig. 2.

\section{Behaviour at elevated temperatures}

\subsection{Thermo-mechanical properties of steel at elevated temperatures}

Steel is characterised by a reduction of yield stress, ultimate stress and Young's modulus with increasing temperature. Coupled with the thermal elongation of steel, this results in steel joints quickly reaching yield under fire conditions, even at con- 


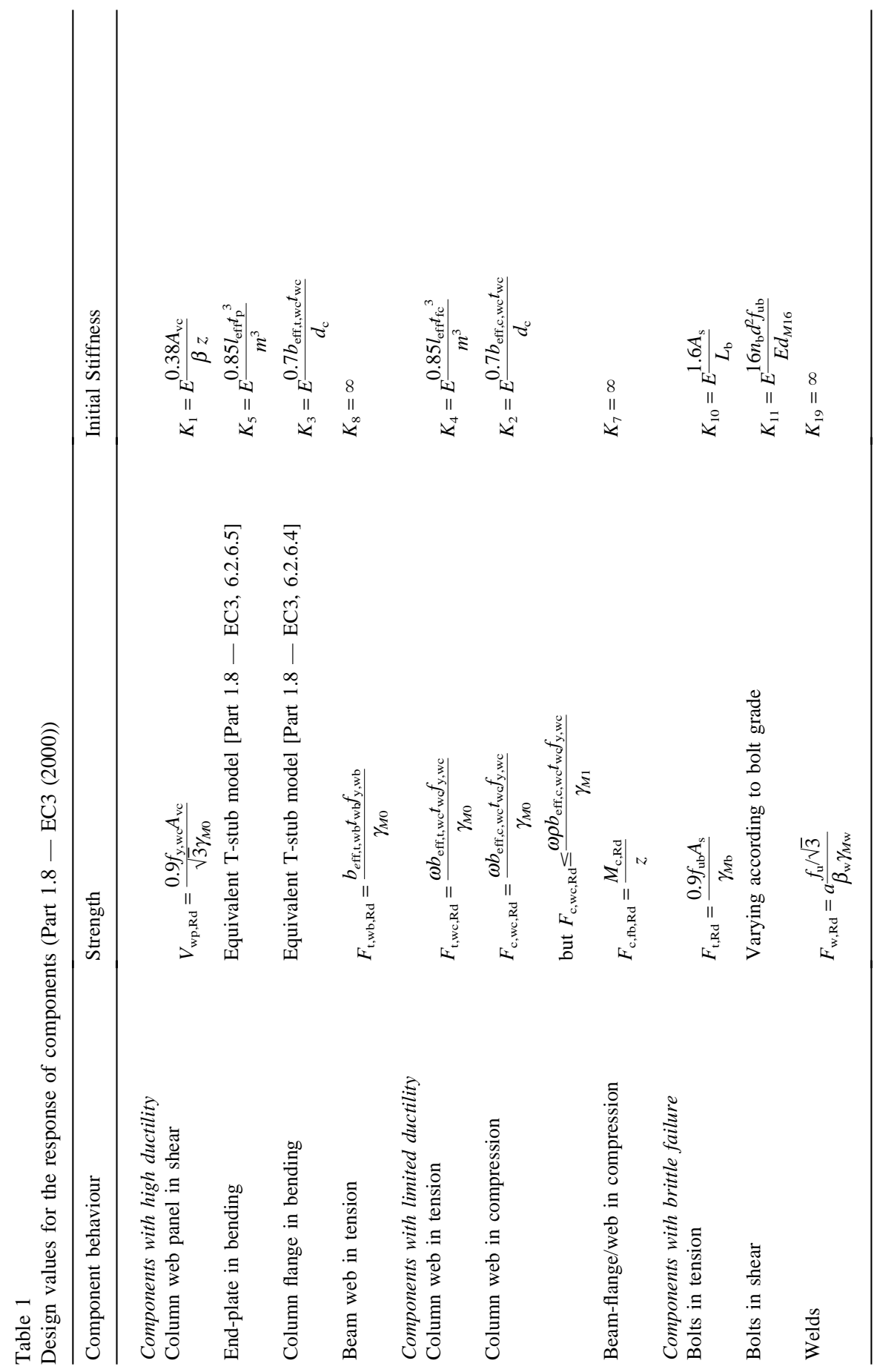




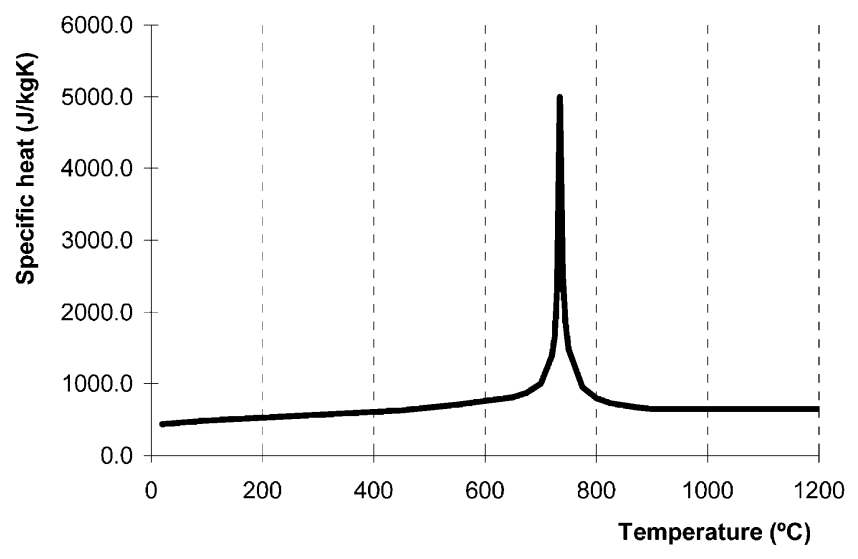

Fig. 6. Specific heat of steel as a function of temperature.

stant mechanical loading. A brief review of thermo-mechanical properties of steel is presented below.

Figs. 6-8 illustrate the variation of specific heat, thermal conductivity and thermal elongation with temperature, analytical expressions for these properties being found in [2].

Similarly, Table 2 reproduces the reduction factors for stiffness and strength of steel with increasing temperature, a reduction of stiffness starting at a temperature of around $200^{\circ} \mathrm{C}$, while strength (yield stress) starts to reduce at about $500^{\circ} \mathrm{C}$. The corresponding stress-strain diagram for steel at elevated temperatures, shown in Fig. 9, exhibits four distinct zones, namely: (i) a linear zone, (ii) an elliptic transition curve, (iii) a constant stress zone, and (iv) a linear softening branch.

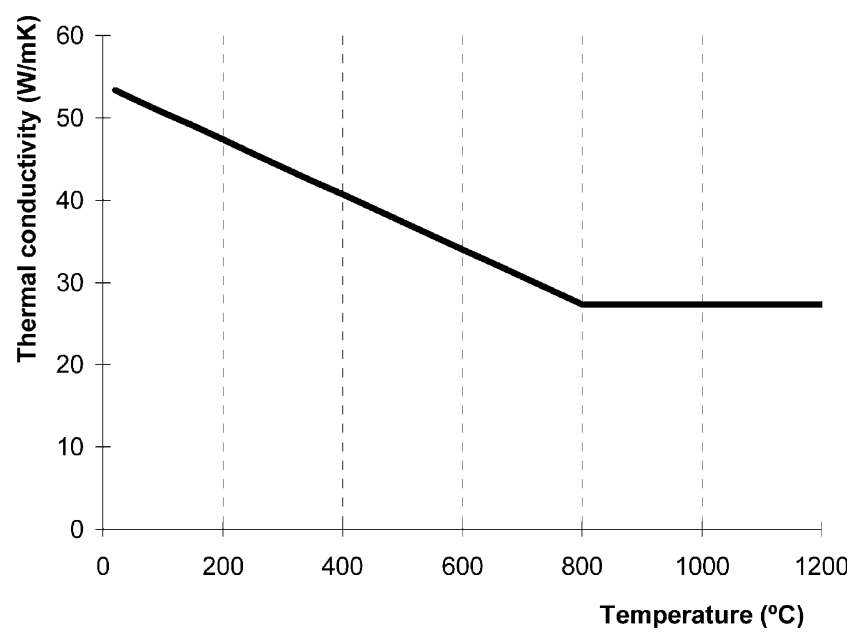

Fig. 7. Thermal conductivity of steel as a function of temperature. 


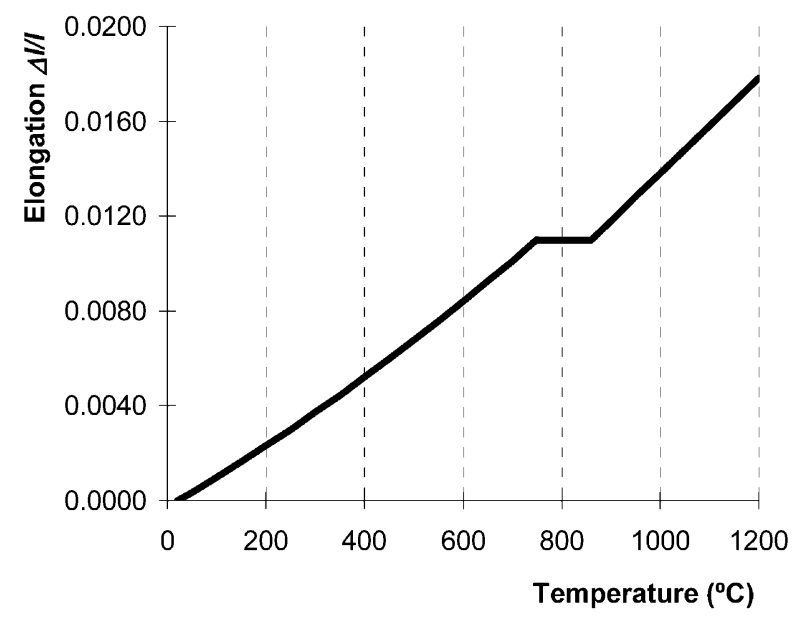

Fig. 8. Thermal elongation of steel as a function of temperature.

Table 2

Reduction factors for stress-strain diagram of steel at elevated temperatures

\begin{tabular}{lll}
\hline Steel temperature, $\theta_{a}$ & \multicolumn{2}{l}{$\begin{array}{l}\text { Reduction factors for yield stress, } f_{\mathrm{y}}, \text { and Young's modulus, } E_{\mathrm{a}} \text {, at } \\
\text { temperature } \theta_{\mathrm{a}}\end{array}$} \\
\cline { 2 - 3 }$\left({ }^{\circ} \mathrm{C}\right)$ & $k_{\mathrm{y}, \theta}=f_{\mathrm{y}, \theta} / f_{\mathrm{y}}$ & $k_{E, \theta}=E_{\mathrm{a}} / E_{a}$ \\
\hline 20 & 1.000 & 1.000 \\
100 & 1.000 & 1.000 \\
200 & 1.000 & 0.900 \\
300 & 1.000 & 0.800 \\
400 & 1.000 & 0.700 \\
500 & 0.780 & 0.600 \\
600 & 0.470 & 0.310 \\
700 & 0.230 & 0.130 \\
800 & 0.110 & 0.090 \\
900 & 0.060 & 0.0675 \\
1000 & 0.040 & 0.0450 \\
1100 & 0.020 & 0.0225 \\
1200 & 0.000 & 0.000 \\
\hline
\end{tabular}

\subsection{Coupled thermo-mechanical load characterisation}

Being two independent processes, mechanical and thermal loading may present arbitrary time histories. For generality, and taking the fire event as the reference, characterised by an arbitrary fire-loading curve, the following situations may arise:

1. mechanical loading takes place before the fire event starts, shown in Fig. 10(a); 


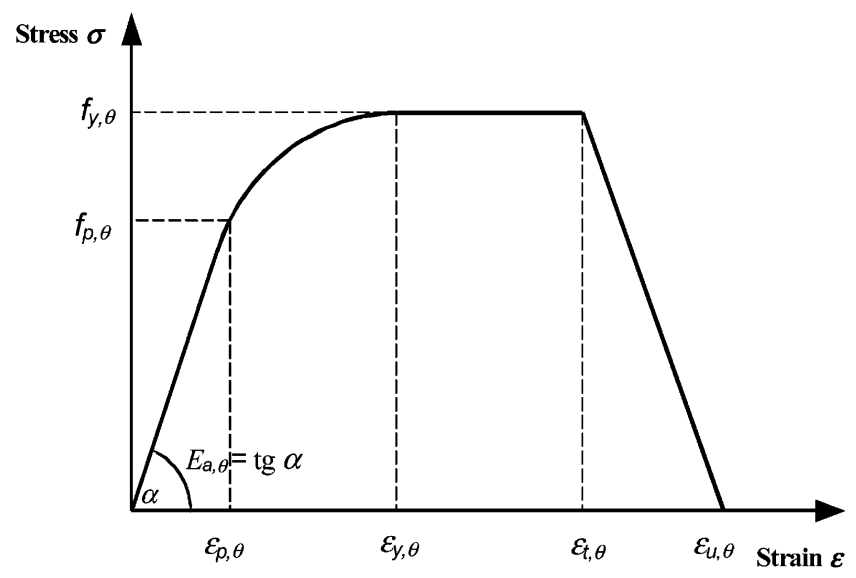

Fig. 9. Stress-strain relationship for steel at elevated temperatures.

(a)

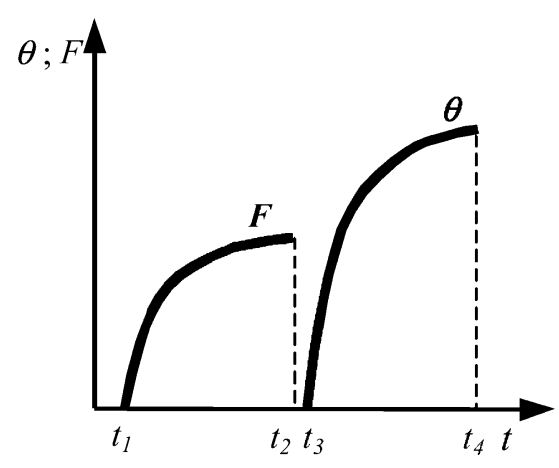

(c) (b)

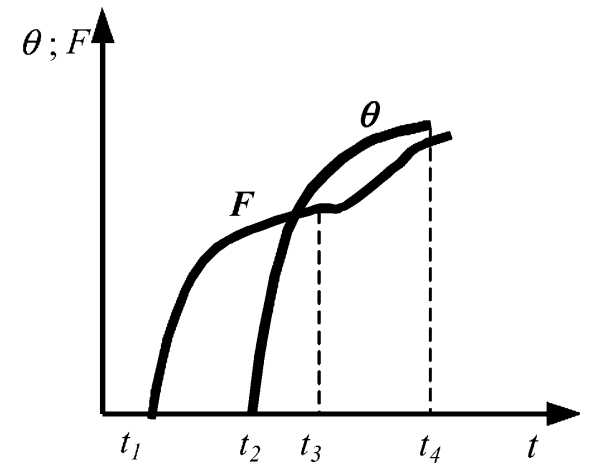

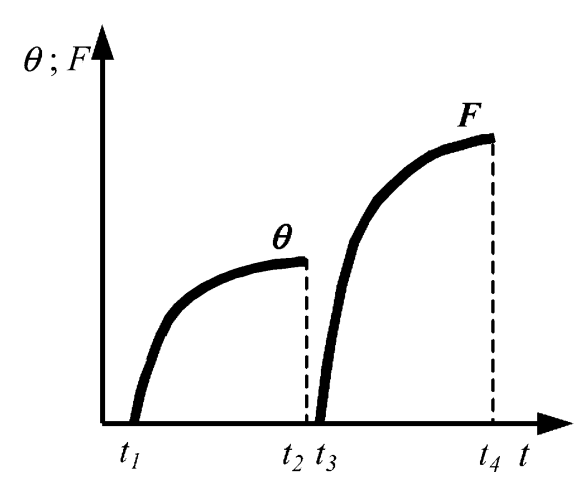

Fig. 10. Variation of thermo-mechanical loading with time: (a) anisothermal; (b) transient; (c) isothermal. 
2. mechanical loading and fire event take place simultaneously (totally or partially); situation illustrated in Fig. 10(b);

3. mechanical loading takes place after fire event has reached its maximum temperature, at sustained temperature conditions, shown in Fig. 10(c).

Naturally, situations (1) and (3) are much simpler and correspond, respectively, to an incremental temperature analysis at constant load level (anisothermal analysis) or an incremental mechanical analysis at constant temperature (isothermal analysis). Here, although case (2) corresponds to the more realistic situation of simultaneous mechanical and thermal loading (transient analysis), corresponding, for example, to the load redistribution that inevitably takes place during a fire event, the two simpler situations will be explored in greater detail.

Table 3

Temperature distribution with time within joint

Authors Temperature distribution

Leston-Jones et al. [5]

Fire tests in double-sided joint with flush end-plate (beam: $254 \times 102 \times 22$ column: $152 \times 152 \times 23$ three bolts M16 (8.8)):

Program the furnace to follow a linear steel temperature path, reaching $900^{\circ} \mathrm{C}$ in $90 \mathrm{~min}$. Average temperature profile for all tests

Lower beam flange $1.000 \times \theta_{\mathrm{fb}}$; upper beam flange $0.677 \times \theta_{\mathrm{fb}}$

Beam centre web $0.985 \times \theta_{\mathrm{fb}}$; top bolt $0.928 \times \theta_{\mathrm{fb}}$

Middle bolt $0.987 \times \theta_{\mathrm{fb}}$; bottom bolt $0.966 \times \theta_{\mathrm{fb}}$

Column flange $1.036 \times \theta_{\mathrm{fb}}$; end plate $0.982 \times \theta_{\mathrm{fb}}$

$\theta_{\mathrm{fb}}$ : Lower beam flange temperature

Al-Jabri et al. [4,20]

Fire tests in steel and composite beam-to-column connections:

Program the furnace to follow a linear steel temperature path, reaching $900^{\circ} \mathrm{C}$ in $90 \mathrm{~min}$. The hottest of the connection elements was the column web. Its temperature ranged between 8 and $26 \%$ higher than beam flange temperature. The presence of the concrete slab above the connections caused a $20-30 \%$ reduction in the beam top flange temperatures.

Lawson [15]

Fire tests on eight beam-to-column connections, typical of those used in modern framed buildings (steel and composite connections):

Average temperature profile for all tests:

$\theta_{\text {lower beam flange }}=650-750^{\circ} \mathrm{C}$

$\downarrow$

$\theta_{\text {upper bolts }}=150-200^{\circ} \mathrm{C}$ lower than $\theta_{\text {lower beam flange }}$

$\theta_{\text {lower bolts }}=100-150^{\circ} \mathrm{C}$ lower than $\theta_{\text {upper bolts }}$

Liu [16]

Numerical modelling of double-sided composite joint with extended endplate:

Connection temperature profile:

For $\approx 45 \mathrm{~min}, \theta_{\text {lower bolts }} \approx 650^{\circ} \mathrm{C} ; \theta_{\text {end plate }} \approx 550^{\circ} \mathrm{C} ; \theta_{\text {upper bolts }} \approx 520^{\circ} \mathrm{C}$;

$\theta_{\text {column web }} \approx 450^{\circ} \mathrm{C} ; \theta_{\text {unexposed bolts }} \approx 350^{\circ} \mathrm{C}$ 
Table 3 (continued)

Authors

SCI recommendation [17]

El-Rimawi et al. [18] Vila Real et al. [19]
Temperature distribution

Joint with extended end-plate, considering embedded top bolts:

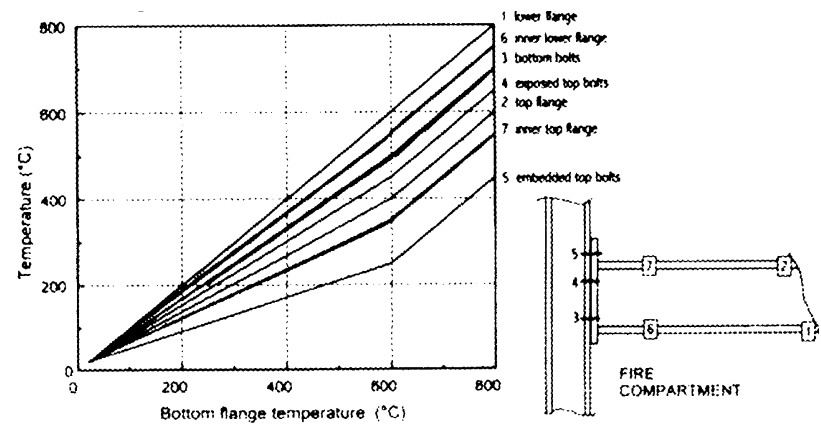

Assumption: $\theta_{\text {upper beam flange }}=0.7 \theta_{\text {lower beam flange }} ; \theta_{\text {upper beam flange }}=0.7 \theta_{\text {beam web }}$ Numerical modelling of HEB400 profiles. Program the furnace to follow a ISO834 fire curve:

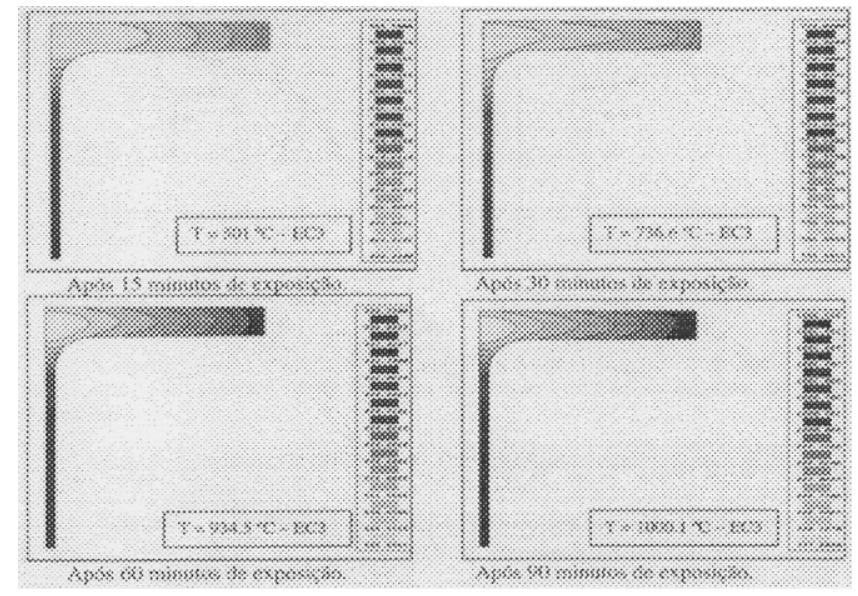

\subsection{Time-temperature variation within the joint}

As described above, the thermal conductivity of steel is high. Nevertheless, because of the mass concentration within the joint area, a differential temperature distribution should be considered within the joint. Various temperature distributions have been proposed or used in experimental tests by several authors, summarised in Table 3, a detailed description being found in the literature [4,5,15-20]. 
Table 4

Differential relative temperature variation within the joint [20]

\begin{tabular}{ll}
\hline Element & Temperature, $\theta$ \\
\hline Beam top & 1.02 \\
Beam web & 1.06 \\
Beam bottom & 1.00 \\
Beam top (insulated) & 0.38 \\
Beam bottom (insulated) & 0.38 \\
Top bolt & 1.04 \\
Middle bolt & 1.03 \\
Bottom bolt & 1.01 \\
Column web & 1.14 \\
Column flange & 1.03 \\
Column insulated & 0.47 \\
End-plate & 1.03 \\
Box & 0.14 \\
\hline
\end{tabular}

Table 3 shows a considerable scatter of results, although, as expected, the bottom part of the joint presents higher temperatures. In the following, two alternative possibilities are considered:

1. Uniform temperature variation within the joint.

2. Differential temperature variation within the joint, obtained from experimental tests [20], summarised in Table 4.

\section{Analytical prediction of fire response of steel joints}

\subsection{Introduction}

As explained above, the evaluation of the fire response of steel joints requires the continuous change of mechanical properties of steel as temperature increases. In the context of the component method, this is implemented at the component level. Noting that the elastic stiffness, $K^{\mathrm{e}}$, is directly proportional to Young's modulus of steel and the resistance of each component depends on the yield stress of steel, Eqs. (1)(3) illustrate the change in component force-deformation response with increasing temperature, for a given temperature variation $\theta$, for component $i$.

$$
\begin{aligned}
F_{i ; \theta}^{y} & =k_{y ; \theta} \times F_{i ; 20^{\circ} \mathrm{C}}^{\mathrm{y}} \\
K_{i ; \theta}^{\mathrm{e}} & =k_{E ; \theta} \times K_{i ; 20^{\circ} \mathrm{C}}^{\mathrm{e}} \\
K_{i ; \theta}^{\mathrm{pl}} & =k_{E ; \theta} \times K_{i ; 20}^{\mathrm{pl}} \mathrm{C}
\end{aligned}
$$

Introducing Eqs. (1)-(3) for the corresponding (constant) values of $K^{\mathrm{e}}, K^{\mathrm{pl}}$ and $F^{\mathrm{y}}$ 
in any evaluation of moment-rotation response of steel joints at room temperature yields the required fire response. Implementation of this procedure in a practical way requires an incremental procedure with sufficiently small temperature increments so that the mechanical properties of steel can be kept constant within each temperature interval, the detailed procedure being explained in the following paragraphs.

\subsection{Isothermal response}

Assuming that the moment-rotation response of a steel joint at room temperature is known, either using a non-linear numerical procedure or the closed-form analytical procedures developed by Silva and Coelho [8], the isothermal response of a steel joint loaded in bending can be obtained as follows, for a constant temperature level, $\theta$.

With reference to Fig. 11, for a given level of applied force $F^{\prime}<F_{i ; \theta}^{\mathrm{y}}$, the component deformation $\Delta_{i ; \theta}^{\prime}$, is given by:

$$
\Delta_{i ; \theta}\left(F^{\prime}\right)=\Delta_{i ; \theta}^{\prime}=\frac{F^{\prime}}{K_{i ; \theta}^{\mathrm{e}}}=\frac{F^{\prime}}{k_{E ; \theta} \times K_{i ; 20^{\circ} \mathrm{C}}^{\mathrm{e}}}=\frac{1}{k_{E ; \theta}} \times \Delta_{i ; 20^{\circ} \mathrm{C}}\left(F^{\prime}\right)
$$

so that the yield deformation becomes

$$
\Delta_{i ; \theta}^{\mathrm{y}}=\frac{F_{i ; \theta}^{\mathrm{y}}}{K_{i ; \theta}^{\mathrm{e}}}=\frac{k_{\mathrm{y} ; \theta}}{k_{E ; \theta}} \Delta_{i ; 20^{\circ} \mathrm{C}}^{\mathrm{y}}
$$

Similarly, for $F^{\prime \prime} \geq F_{i ; \theta}^{\mathrm{y}}$

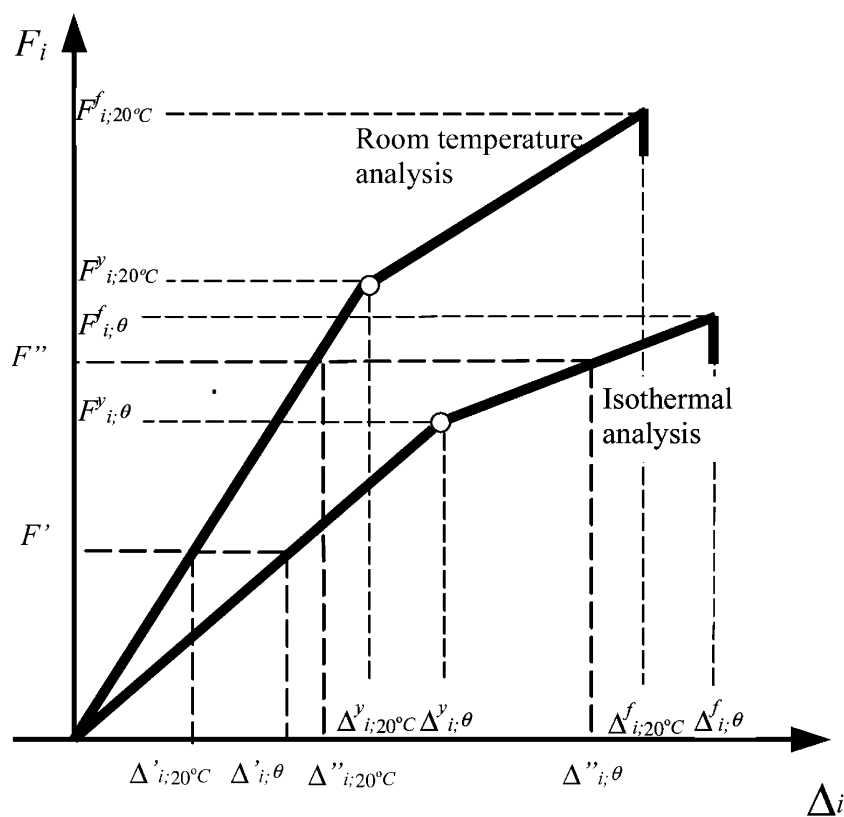

Fig. 11. Isothermal force-deformation response of component. 


$$
\begin{aligned}
& \Delta_{i ; \theta}\left(F^{\prime \prime}\right)=\Delta^{\prime \prime}{ }_{i ; \theta} \\
& =\Delta_{i ; \theta}^{\mathrm{y}}+\frac{1}{k_{E ; \theta}} \times \frac{F^{\prime \prime}-F_{i ; \theta}^{\mathrm{y}}}{K_{i ; 20^{\circ} \mathrm{C}}^{\mathrm{p}}}=\Delta_{i ; \theta}^{\mathrm{y}}+\frac{1}{k_{E ; \theta}} \times \frac{\Delta_{i ; 20^{\circ} \mathrm{C}}^{\mathrm{f}}-\Delta_{i ; 20}^{y} \mathrm{C}}{F_{i ; 20^{\circ} \mathrm{C}}^{\mathrm{f}}-F_{i ; 20^{\circ} \mathrm{C}}^{\mathrm{y}}}\left(F^{\prime \prime}-F_{i ; \theta}^{\mathrm{y}}\right)
\end{aligned}
$$

From equilibrium considerations, and within the scope of the ductility model presented in [8], the bending moment for a given level of joint deformation is given by:

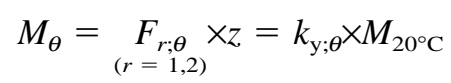

$F_{1 ; \theta}=F_{2 ; \theta}$ and $F_{r ; \theta}$ and $z$ being defined in Fig. 12. From Eq. (7), it follows directly that, at yielding of an arbitrary component,

$$
M_{i ; \theta}^{\mathrm{y}}=k_{\mathrm{y} ; \theta} \times M_{i ; 20^{\circ} \mathrm{C}}^{\mathrm{y}}
$$

Similar expressions can be derived for stiffness and rotation of the joint, as will be demonstrated below using a recursive technique. According to [3], the initial stiffness of a joint loaded in bending is given by:

$$
S_{1}=S_{\mathrm{j}, \text { ini }}=\frac{E \times z^{2}}{\sum_{i} \frac{1}{k_{i}}}
$$

so that, at temperature $\theta$,

$$
S_{1 ; \theta}=\frac{E_{\theta} z^{2}}{\sum_{i} \frac{1}{k_{i ; \theta}}}=k_{E ; \theta} \times S_{1 ; 20^{\circ} \mathrm{C}}
$$

The rotation at yield of the first component follows from

$$
\phi_{1 ; \theta}^{\mathrm{y}}=\frac{M_{1 ; \theta}^{\mathrm{y}}}{S_{1 ; \theta}}=\frac{k_{\mathrm{y} ; \theta}}{k_{E ; \theta}} \times \phi_{1 ; 20^{\circ} \mathrm{C}}^{\mathrm{y}}
$$
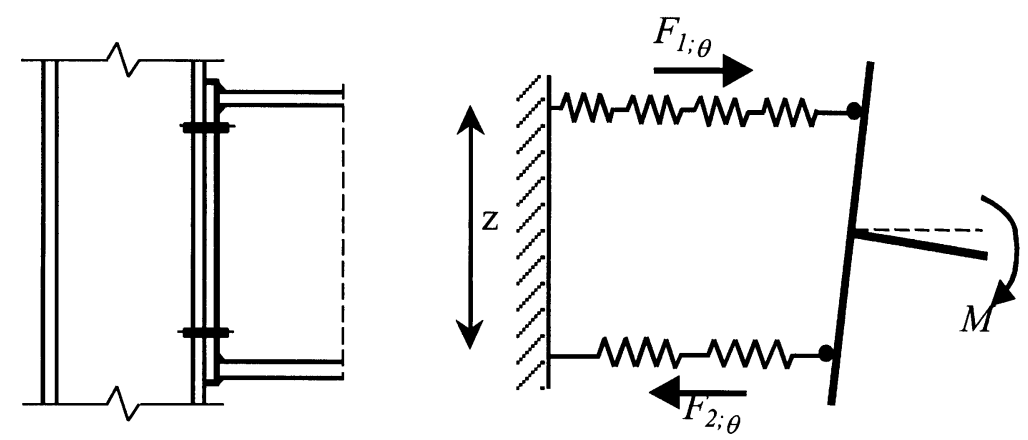

Fig. 12. Axial forces in tensile and compressive zones of a joint. 
Assuming that the following equations hold for segment $s$, as shown in Fig. 13,

$$
\begin{aligned}
& S_{s ; \theta}=k_{E ; \theta} \times S_{s ; 20^{\circ} \mathrm{C}} \\
& \phi_{s ; \theta}^{\mathrm{y}}=\frac{k_{\mathrm{y} ; \theta}}{k_{E ; \theta}} \times \phi_{s ; 20^{\circ} \mathrm{C}}^{\mathrm{y}} ;
\end{aligned}
$$

defining

$$
\bar{\phi}_{s+1 ; \theta}^{\mathrm{y}}=\phi_{s+1 ; \theta}^{\mathrm{y}}-\phi_{s ; \theta}^{\mathrm{y}}
$$

and since

$$
\bar{S}_{s+1 ; \theta}=\frac{M_{s+1 ; \theta}^{\mathrm{y}}-M_{s ; \theta}^{\mathrm{y}}}{\bar{\phi}_{s+1 ; \theta}^{\mathrm{y}}} \Rightarrow \bar{\phi}_{s+1 ; \theta}^{\mathrm{y}}=\frac{M_{s+1 ; \theta}^{\mathrm{y}}-M_{s ; \theta}^{\mathrm{y}}}{\bar{S}_{s+1 ; \theta}}
$$

it follows, for segment $s+1$,

$$
\bar{S}_{s+1 ; \theta}=\frac{E_{\theta} \times z^{2}}{\left(\sum_{i=1}^{s} \frac{1}{k_{i}^{\mathrm{p}}}+\sum_{i=s+1}^{n} \frac{1}{k_{i}^{\mathrm{e}}}\right)}
$$

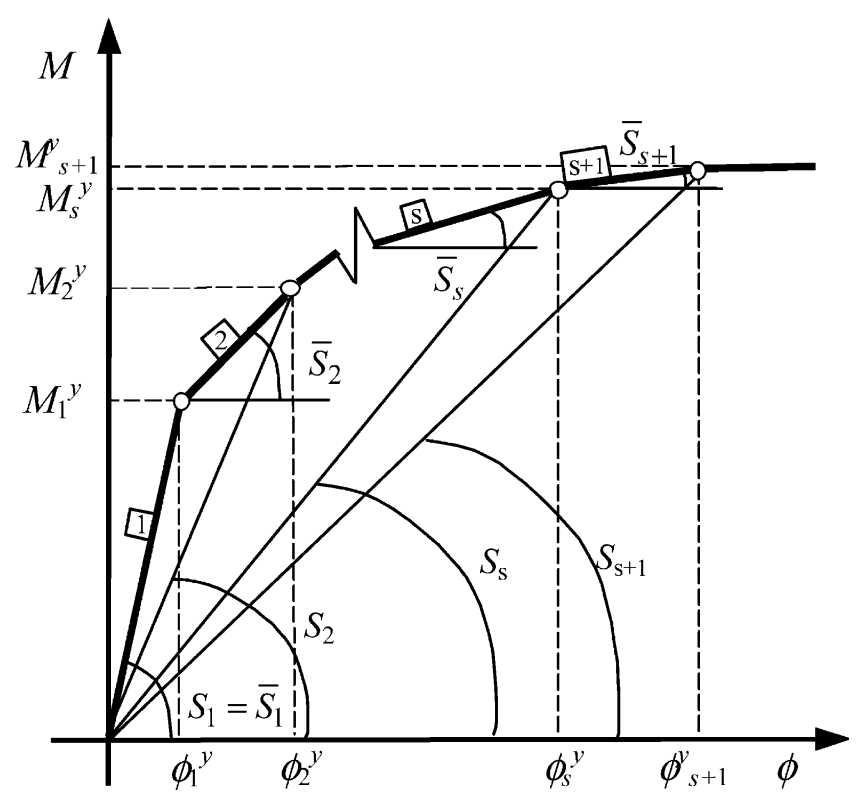

Fig. 13. Isothermal moment-rotation response of joint. 


$$
\begin{aligned}
& S_{s+1 ; \theta}=\frac{M_{s+1 ; \theta}^{\mathrm{y}}}{\phi_{s+1 ; \theta}^{\mathrm{y}}}=\frac{M_{s+1 ; \theta}^{\mathrm{y}}}{\phi_{s ; \theta}^{\mathrm{y}}+\bar{\phi}_{s+1 ; \theta}^{\mathrm{y}}} \\
& =\frac{k_{\mathrm{y} ; \theta} \times M_{s+1 ; 20{ }^{\circ} \mathrm{C}}^{\mathrm{y}}}{\frac{k_{\mathrm{y} ; \theta}^{\mathrm{y}} \times \phi_{s ; 20^{\circ} \mathrm{C}}}{k_{E ; \theta}}+\frac{k_{\mathrm{y} ; \theta} \times\left(M_{s}^{\mathrm{y}}+1 ; 20^{\circ} \mathrm{C}-M_{s ; 20}^{\mathrm{y}} \mathrm{C}\right)}{k_{E ; \theta}^{2} \times E \times z}}=k_{E ; \theta} \times S_{s+1 ; 20^{\circ} \mathrm{C}} \\
& \left(\sum_{i=1}^{s} \frac{1}{k_{i}^{\mathrm{p}}}+\sum_{i=s+1}^{n} \frac{1}{k_{i}^{\mathrm{e}}}\right) \\
& \phi_{i ; \theta}^{\mathrm{y}}=\frac{M_{i ; \theta}^{\mathrm{y}}}{S_{i ; \theta}^{\mathrm{y}}}=\frac{k_{\mathrm{y}, \theta} \times M_{i ; 20^{\circ} \mathrm{C}}^{\mathrm{y}}}{k_{E, \theta} \times S_{i ; 20^{\circ} \mathrm{C}}}=\frac{k_{\mathrm{y} ; \theta}}{k_{E ; \theta}} \times \phi_{i ; 20^{\circ} \mathrm{C}}^{y}
\end{aligned}
$$

$n$ being the total number of components. Eqs. (7)-(18) give the generic momentrotation curve at constant temperature $\theta$, where the yielding sequence of the various components is identified, as shown schematically in Fig. 13.

\subsection{Anisothermal response}

Under anisothermal conditions, i.e., when subject to increasing temperature under constant load level, the progressive degradation of material properties eventually leads to the degradation of the resistance, excessive deformation and finally collapse of the joint, as illustrated in Fig. 14. At collapse, the joint reaches temperature $\theta_{\mathrm{f}}$, called the critical temperature of the joint [2]. For a joint under uniform temperature distribution, the critical temperature is defined as the maximum temperature of the joint corresponding to failure of the joint,

$$
M_{\mathrm{j}, \mathrm{Sd}}=M_{\mathrm{j}, \mathrm{max} ; \theta_{\mathrm{f}}}
$$

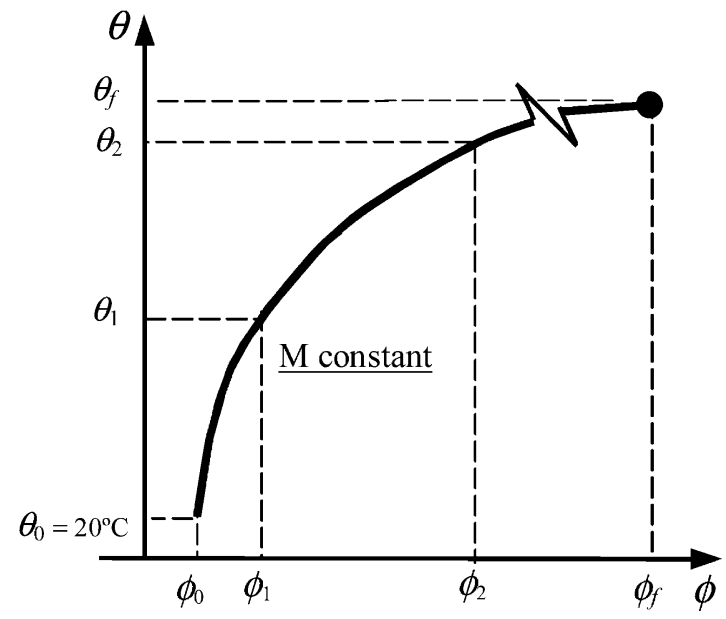

Fig. 14. Anisothermal temperature-rotation response of joint. 
where $M_{\mathrm{j}, \mathrm{Sd}}$ is the applied bending moment and $M_{\mathrm{j}, \text { max } ; \theta_{\mathrm{f}}}$, denotes the maximum moment at temperature $\theta_{\mathrm{f}}$.

According to [2], the evaluation of the critical temperature requires the calculation of the degree of utilisation of the joint at time $t=0, \mu_{0}$, defined as the ratio between the design effect of the actions for the fire design situation and the design resistance of the steel member, for the fire design situation, at time $t$. For the present case of steel joints, and considering the nomenclature used in this paper, the degree of utilisation is explicitly given by:

$$
\mu_{0}=\frac{M_{\mathrm{j}, \mathrm{Sd}}}{M_{\mathrm{j}, \max ; 20^{\circ} \mathrm{C}}}
$$

For elements with uniform temperature distribution, the degradation of the resistance with time is proportional to the decrease in yield stress of steel; see Eq. (1). Eq. (19) can thus be re-written in the following way:

$$
\mu_{0} \times M_{\mathrm{j}, \max ; 20^{\circ} \mathrm{C}}=k_{\mathrm{y} ; \theta_{\mathrm{f}}} \times M_{\mathrm{j}, \max ; 20^{\circ} \mathrm{C}}
$$

leading to:

$$
\mu_{0}=k_{\mathrm{y} ; \theta_{\mathrm{f}}}
$$

Given that, under anisothermal conditions, the degree of utilisation is known a priori, Eq. (22) allows the direct calculation of the critical temperature of the joint using Table 2. The corresponding joint rotation follows directly using Eq. (18).

To identify the temperature and rotation corresponding to the yield points of the various components, a degree of partial utilisation is herein proposed, leading to the following equation using a similar procedure:

$$
\mu_{0 i}=\frac{M_{\mathrm{j}, \mathrm{Sd}}}{M_{i ; 20^{\circ} \mathrm{C}} \mathrm{y}}=k_{\mathrm{y} ; \theta_{\mathrm{y} i}}
$$

where $M_{i ; 20^{\circ} \mathrm{C}}$, is the bending moment at yield of component $i$, at ambient temperature.

\section{Application to cruciform bolted end-plate beam-to-column steel joint}

In order to illustrate the evaluation of the moment-rotation response of steel joints under fire loading, a cruciform bolted end-plate beam-to-column steel joint configuration experimentally tested by Al-Jabri et al. [20] was selected. This major axis joint configuration consists of two $254 \times 102$ UB22 beams connected to a $152 \times 152$ UC23 column by $8 \mathrm{~mm}$ thick flush end plates. The joint details are shown in Fig. 15 and Table 5. The elevated temperature tests were performed under anisothermal conditions, the levels of applied bending moment being based on a calculated moment capacity of the joint at ambient temperature: $20 \mathrm{kNm}$ [20]. Four situations were studied (Table 5): $4 \mathrm{kNm}\left(M_{j, \mathrm{Sd}} / M_{j, \mathrm{Rd}, 20^{\circ} \mathrm{C}}=0.2\right), 8 \mathrm{kNm}\left(M_{j, \mathrm{Sd}} / M_{j, \mathrm{Rd}, 20^{\circ} \mathrm{C}}=0.4\right), 12.8$ 


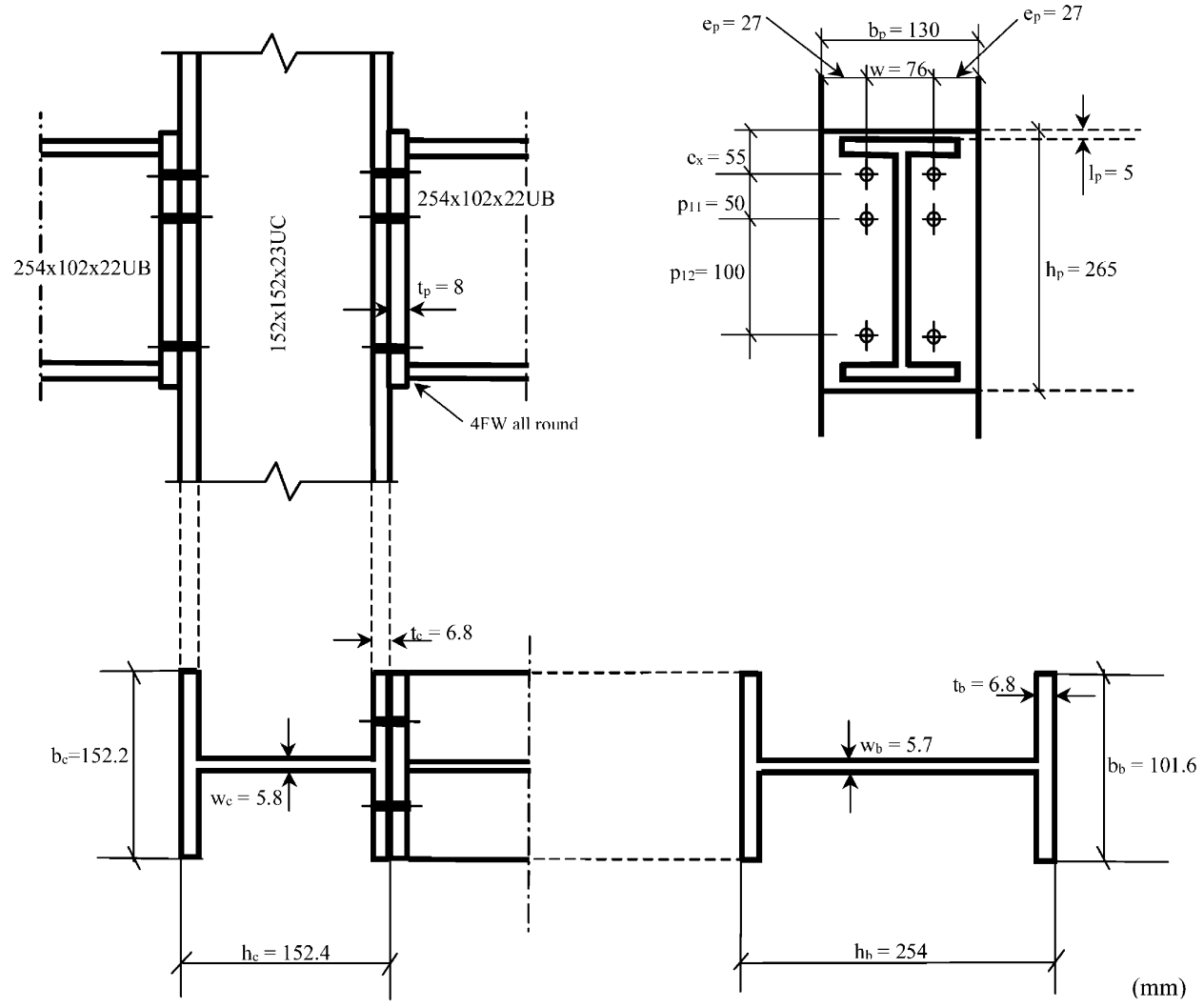

Fig. 15. Details of selected joint [20].

Table 5

Details of selected tests

\begin{tabular}{lllllll}
\hline Test & End-plate & Beam & Column & Material & Bolt & $\begin{array}{l}\text { Load } \\
\text { level }\end{array}$ \\
\hline FB11 & $\begin{array}{l}\text { Flush end-plates } \\
(265 \times 130 \times 8)\end{array}$ & $254 \times 102 \times 22 \mathrm{UB}$ & $152 \times 152 \times 23 \mathrm{UC}$ & $\begin{array}{l}f_{\mathrm{y}}=322, \\
f_{\mathrm{u}}=454 \mathrm{Mpa} \\
f_{\mathrm{y}}=322, \\
f_{\mathrm{u}}=454 \mathrm{Mpa}\end{array}$ & 8.8 & $0.2 M_{\mathrm{j}, \mathrm{Rd}}$ \\
FB12 & $\begin{array}{l}\text { Flush end-plates } \\
(265 \times 130 \times 8)\end{array}$ & $254 \times 102 \times 22 \mathrm{UB}$ & $152 \times 152 \times 23 \mathrm{UC}$ & $0.4 M_{\mathrm{j}, \mathrm{Rd}}$ \\
FB13 & $\begin{array}{l}\text { Flush end-plates } \\
(265 \times 130 \times 8)\end{array}$ & $254 \times 102 \times 22 \mathrm{UB}$ & $152 \times 152 \times 23 \mathrm{UC}$ & $\begin{array}{l}f_{\mathrm{y}}=322, \\
f_{\mathrm{u}}=454 \mathrm{Mpa}\end{array}$ & 8.8 & $0.64 M_{\mathrm{j}, \mathrm{Rd}}$ \\
FB14 & $\begin{array}{l}\text { Flush end-plates } \\
(265 \times 130 \times 8)\end{array}$ & $254 \times 102 \times 22 \mathrm{UB}$ & $152 \times 152 \times 23 \mathrm{UC}$ & $\begin{array}{l}f_{\mathrm{y}}=322, \\
f_{\mathrm{u}}=454 \mathrm{Mpa}\end{array}$ & 8.8 & $0.85 M_{\mathrm{j}, \mathrm{Rd}}$ \\
\hline
\end{tabular}


$\operatorname{kNm}\left(M_{j, \mathrm{Sd}} / M_{j, \mathrm{Rd}, 20^{\circ} \mathrm{C}}=0.64\right)$ and $17 \mathrm{kNm}\left(M_{j, \mathrm{Sd}} / M_{j, \mathrm{Rd}, 20^{\circ} \mathrm{C}}=0.85\right)$, where $M_{j, \mathrm{Sd}}$, is the applied moment.

In order to compare these experimental results with the present analytical procedures, and in the context of the component method, the spring and rigid link model of Fig. 1 was adopted. Unfortunately, according to [20], due to the limited number of specimens available, no ambient temperature test was carried out (room temperature results being only available for test FB14, up to the chosen applied level of bending moment, $17 \mathrm{kNm}$ ). Because this joint configuration was based on a previous test program carried out by Leston-Jones et al. [5], that only differed by the use of a larger end-plate thickness (12 $\mathrm{mm}$ versus the $8 \mathrm{~mm}$ of the current tests), the required calibration of the post-limit stiffness of the various components at ambient temperature was carried out for this test (Lee test), as illustrated in Fig. 16. Table 6 reproduces the required properties at ambient temperature for the various components. Table 7 summarises the resistance and initial stiffness values calculated for this case using the EC3 specifications, and the initial stiffness obtained with a non-linear numerical calculation. Table 8 reproduces the yield sequence of the various components, showing yielding of the column flange in bending at the level of the first boltrow (4.1), end-plate in bending at the level of the first bolt-row (5.1), column flange in bending at the level of the second bolt-row (4.2), column web in compression (2) and, finally, failure of the joint.

Comparing the elevated temperature tests (under isothermal conditions) with the analytical results assuming a uniform temperature distribution across the joint yields the results of Fig. 17. For all cases, the same sequence of yielding of the various components is observed, column flange in bending at the level of the first bolt-row (4.1), end-plate in bending at the level of the first bolt-row (5.1), column flange in bending at the level of the second bolt-row (4.2) and column web in compression

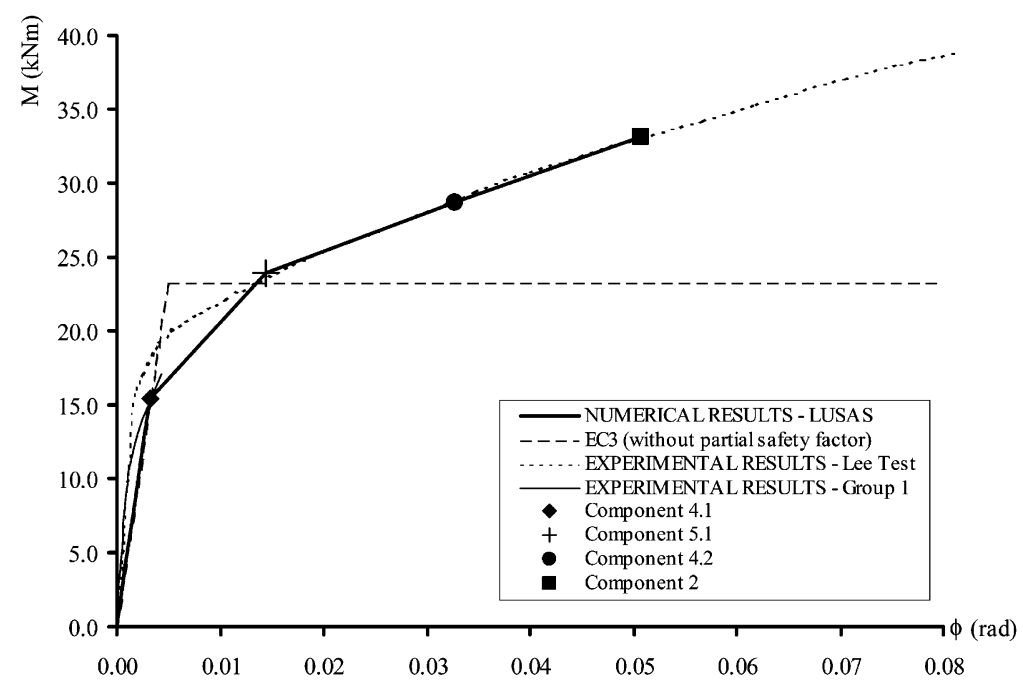

Fig. 16. Calibration of joint moment-rotation response at ambient temperature. 
Table 6

Characterisation of components for cruciform bolted end-plate joint

\begin{tabular}{lcclll}
\hline Component & Designation & $F^{\mathrm{y}}(\mathrm{kN})$ & $K^{\mathrm{e}}(\mathrm{kN} / \mathrm{m})$ & $K^{\mathrm{pl}}(\mathrm{kN} / \mathrm{m})$ & $\Delta(\mathrm{mm})$ \\
\hline Column web in & 2 & 181.15 & 678,300 & $15,073.33$ & 0.267 \\
compression & & & & & \\
Column web in tension & 3.1 & 305.74 & 737,100 & Not relevant & 0.415 \\
& 3.2 & 305.74 & 516,600 & Not relevant & 0.591 \\
Column flange in bending & 4.1 & 54.82 & 245,700 & $12,766.31$ & 0.223 \\
& 4.2 & 54.82 & 172,200 & $11,096.28$ & 0.318 \\
End-plate in bending & 5.1 & 85.18 & 352,800 & 8681.09 & 0.241 \\
& 5.2 & 85.18 & 239,400 & Not relevant & 0.356 \\
Beam web in tension & 7.1 & 295.40 & $\infty$ & Not relevant & \\
& 7.2 & 295.40 & $\infty$ & Not relevant & \\
Beam flange in & 8.1 & 293.88 & $\infty$ & Not relevant & \\
compression & & & & & Not relevant \\
Bolts in tension & 8.2 & 293.88 & $\infty$ & 1 & 0.216 \\
& 10.1 & 226.08 & $1,047,900$ & 1 & 0.216 \\
\hline
\end{tabular}

Table 7

Resistance and initial stiffness at ambient temperature

\begin{tabular}{ll}
\hline Numerical model & EC3 \\
\hline$S_{\mathrm{j}, \text { ini }}=4825.16 \mathrm{kNm} / \mathrm{rad}$ & $M_{\mathrm{j}, \mathrm{Rd}}=23.30 \mathrm{kNm}$ \\
& $S_{\mathrm{j}, \text { ini }}=4730.00 \mathrm{kNm} / \mathrm{rad}$ \\
\hline
\end{tabular}

Table 8

Yield points at ambient temperature

\begin{tabular}{lll}
\hline Component yielding sequence & Moment $(\mathrm{kNm})$ & Rotation $(\mathrm{rad})$ \\
\hline Component 4.1 & 15.43 & 0.00320 \\
Component 5.1 & 23.98 & 0.01448 \\
Component 4.2 & 28.70 & 0.03231 \\
Component 2 & 33.13 & 0.05067 \\
\hline
\end{tabular}

(2), in good agreement with the experimental results. As the temperature increases, the moment resistance of the joint progressively decreases, the strength of the joint becoming negligible for temperatures above $900^{\circ} \mathrm{C}$. Figs. 18 and 19 show the variation of initial stiffness and maximum moment with temperature increase.

For all cases, the analytical results systematically exhibit higher strength and stiffness, reflecting the unconservative assumption of uniform temperature distribution. In fact, examination of Table 4 reveals temperature differences of about $15 \%$ across the joint, the minimum temperature being observed at the bottom flange level, taken as the reference in the previous simulation under the assumption of uniform tempera- 


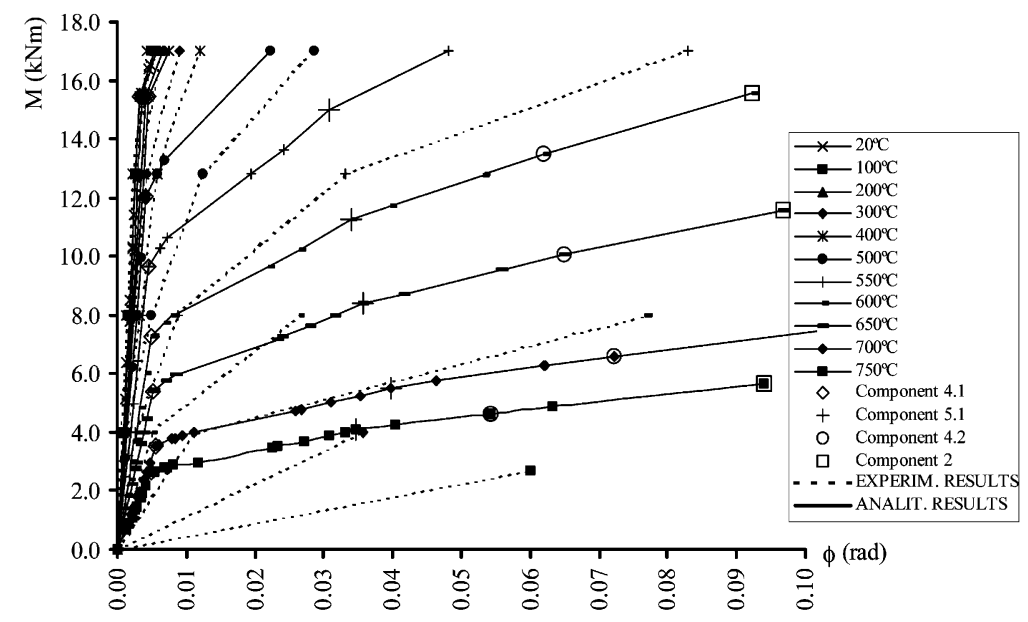

Fig. 17. Isothermal moment-rotation response (uniform temperature distribution across joint).

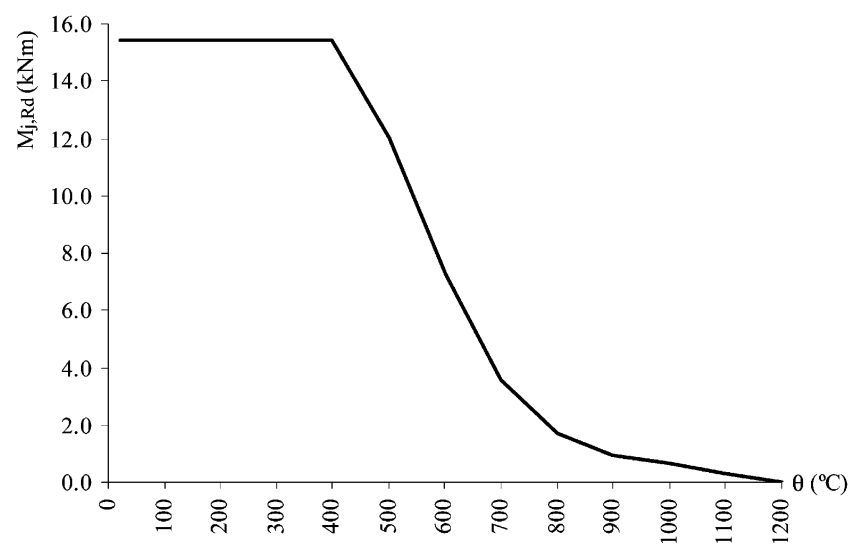

Fig. 18. Variation of moment resistance with temperature.

ture distribution. Although one possibility to improve this situation would be to implement a differential temperature distribution component by component, a simpler alternative was chosen here: application of a global temperature correction coefficient, calibrated with the observed temperature distribution and the experimental results. Fig. 20 illustrates the corresponding results, obtained for a temperature correction coefficient of $7.5 \%$. Good agreement is observed between the experimental and analytical results.

The same joints analysed under anisothermal loading exhibit the results illustrated in Fig. 21 and Table 9, obtained for the same correction coefficient of 7.5\%, again showing good agreement with the experimental results. 


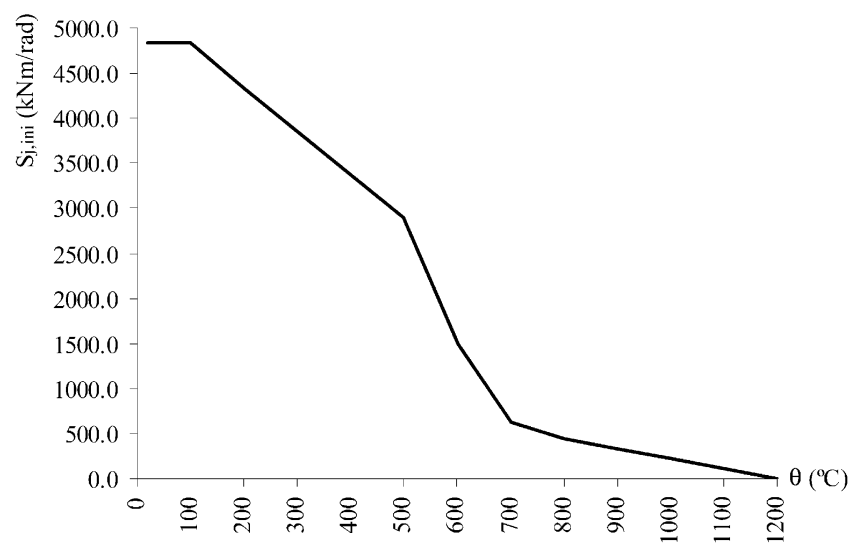

Fig. 19. Variation of initial stiffness with temperature.

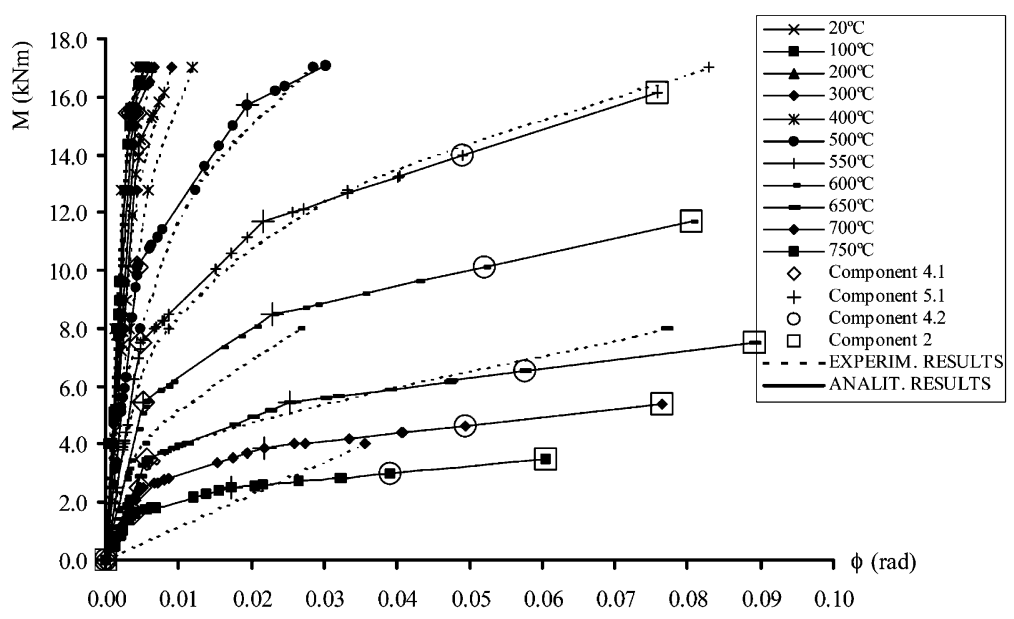

Fig. 20. Isothermal moment-rotation response (with temperature correction coefficient=0.925).

\section{Concluding remarks}

The fire response of steel joints involves additional complexity to the corresponding cold analysis. An analytical procedure for the evaluation of the behaviour of steel joints under fire loading was proposed in this paper. This analytical methodology greatly simplifies this problem, allowing a direct solution from the knowledge of the response at ambient temperature. Coupled with recently developed closedform analytical procedures $[8,14]$, for the evaluation of the non-linear momentrotation response of steel joints in the context of the component method, this should provide a useful solution to an otherwise untractable problem.

Comparison with experimental results available in the literature has shown good agreement with the proposed method. Naturally, some aspects still remain to be 


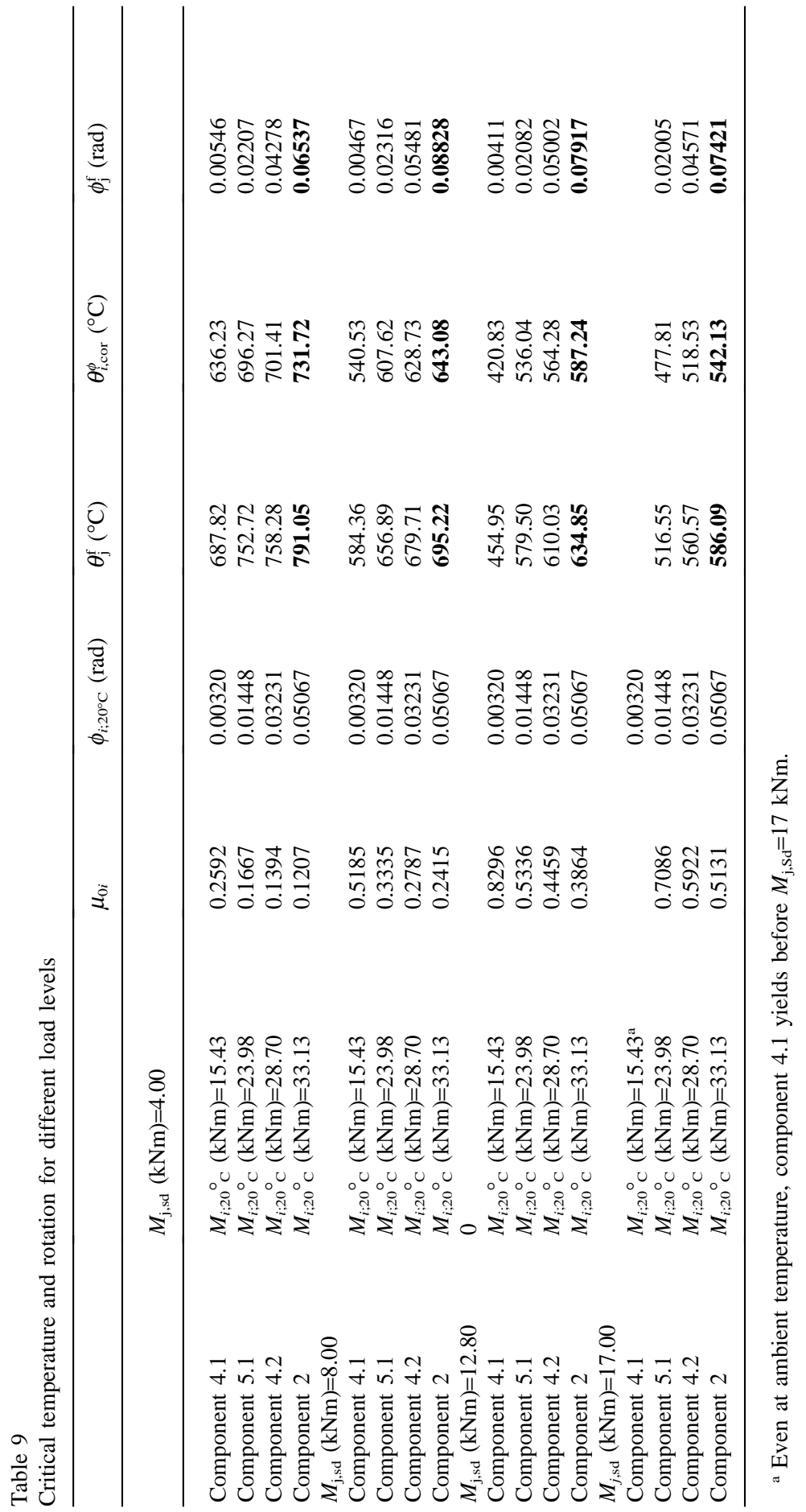




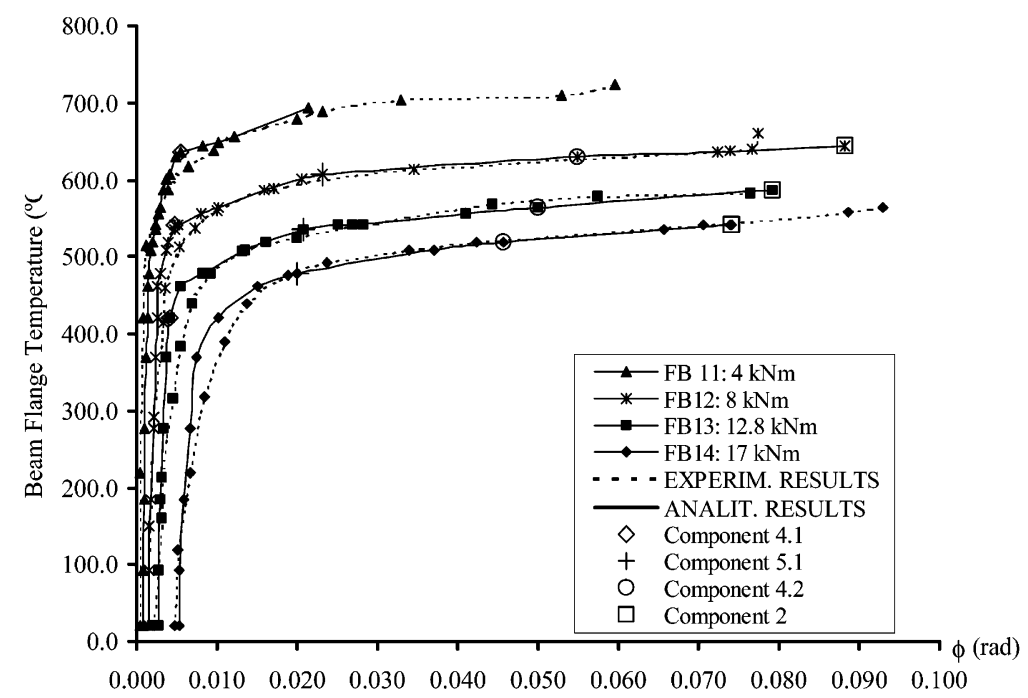

Fig. 21. Anisothermal temperature-rotation response (with temperature correction coefficient=0.925)

improved: as noted before, the thermal elongation of the various joint components was not considered in this paper, not because of any fundamental difficulty in incorporating it in the analysis (an additional term would suffice in the force-deformation relation for each component), but because of lack of calibration in the actual thermal deformation of each component, an issue that requires extensive numerical and experimental research.

Finally, it is noted that the issue of transient loading offers no fundamental complexity, solution being possible from a set of isothermal results, although direct analytical expressions are also available [21].

\section{Acknowledgements}

Financial support from Ministério da Ciência e Tecnologia PRAXIS XXI research project PRAXIS/P/ECM/13153/1998 is acknowledged.

\section{References}

[1] Al-Jabri KS, Burgess IW, Lennon T, Plank RJ. The performance of frame connections in fire. In: Proceedings Eurosteel '99; Praha, Czech Republic, 1999. pp. 519-22.

[2] Eurocode 3, ENV-1993-1-2: Design of steel structures. Part 1.2: General rules — structural fire design. Document CEN/TC 250/SC 3. Brussels: CEN, European Committee for Standardisation; 1995.

[3] Eurocode 3, prEN-1993-1-8: 20xx. Part 1.8: Design of joints. Eurocode 3: Design of steel structures, draft 2 rev., 6 December. Brussels: CEN, European Committee for Standardisation; 2000. 
[4] Al-Jabri KS, Burgess IW, Lennon T, Plank RJ. Behaviour of steel and composite beam-column connections in fire. J. Construct. Steel Res. 1998;46:1-3.

[5] Leston-Jones LC, Burgess W, Lennon T, Plank RJ. Elevated temperature moment-rotation tests on steelwork connections. Proc. Institution of Civil Engineers, Structures and Buildings 1997;122(4):410-9.

[6] Kuhlmann U, Davison JB, Kattner M. Structural systems and rotation capacity. In: COST Conference; Liège, Belgium, 1998. pp. 167-76.

[7] Eurocode 4, prEN-1994-1-1: 200xx. Part 1.1: General rules and rules for buildings. Eurocode 4: Design of composite steel and concrete structures, draft 1. Brussels: CEN, European Committee for Standardisation; 1999.

[8] Simões da Silva L, Girão Coelho A. A ductility model for steel connections. J. Construct. Steel Res. 2001;57:45-70.

[9] Drysdale DD. An introduction to fire dynamics, 2nd ed. West Sussex, UK: John Wiley \& Sons, 1999.

[10] Weynard K, Jaspart J-P, Steenhuis M. The stiffness model of revised Annex J of Eurocode 3. In: Bjorhovde R, Colson A, Zandonini R, editors. Proceedings of the 3rd International Workshop on Connections; Trento, Italy, 1995. pp. 441-52.

[11] Zoetemeijer P. A design method for the tension side of statically-loaded, bolted beam-to-column connections. Heron 1974;20(1):1-59.

[12] Jaspart J-P. Etude de la semi-rigidité des noeuds poutre-colonne et son influence sur la resistance des ossatures en acier. PhD Thesis, Department MSM, University of Liége, Belgium; 1991 [in French].

[13] Jaspart J-P. Contributions to recent advances in the field of steel joints. Column bases and further configurations for beam-to-column joints and beam splices. Professorship Thesis, Université de Liège, Belgium; 1998.

[14] Simões da Silva L, Girão Coelho A, Neto E. Equivalent post-buckling models for the flexural behaviour of steel connections. Comput. Struct. 2000;77:615-24.

[15] Lawson RM. Behaviour of steel beam-to-column connections in fire. The Structural Engineer 1990;68(14):263-71.

[16] Liu TCH. Finite element modelling of behaviour of steel beams and connections in fire. J. Construct. Steel Res. 1996;36(2):181-99.

[17] The Steel Construction Institute. Enhancement of fire resistance of beams by beam to column connections. Technical report, SCI Publication 086; 1990.

[18] El-Rimawi JA, Burgess IW, Plank RJ. The influence of connections stiffness on the behaviour of steel beams in fire. J. Construct. Steel Res. 1997;43(1-3):1-15.

[19] Vila Real PMM, Oliveira CAM. Numerical modelling of the thermal behaviour of steel and composite cross-sections under fire loading. In: Lamas A, Cruz P, Calado L, editors. Proceedings of Construção Metálica e Mista 1; Porto, 1997. pp. 563-74 [in Portuguese].

[20] Al-Jabri KS, Burgess IW, Plank RJ. Behaviour of steel and composite beam-to-column connections in fire, vol. 1. Research report DCSE/97/F/7. Department of Civil and Structural Engineering, University of Sheffield; 1997.

[21] Santiago A. Behaviour of steel joints under fire loading. MSc Thesis, Department of Civil Engineering, University of Coimbra; 2000 [in Portuguese]. 